\title{
PENGARUH E-SERVICE QUALITY DAN E-RECOVERY SERVICE QUALITY TERHADAP E-CUSTOMER SATISFACTION DAN E-CUSTOMER LOYALTY
}

\author{
Suci Rizka Khairuna Tambusai ${ }^{1}$, Suharyono ${ }^{2}$, Edriana Pangestuti ${ }^{3}$ \\ Fakultas Ilmu Administrasi, Universitas Brawijaya, Malang, Indonesia ${ }^{123}$ \\ Email: sucirizka17@gmail.com ${ }^{1}$, sharyonofia@ub.ac.id ${ }^{2}, \underline{\text { edriana_fia@ub.ac.id }}{ }^{3}$
}

\begin{abstract}
The purpose of this study is to find the impact of e-service quality and e-recovery service quality on ecustomer satisfaction and e-customer loyalty in Shopee's online marketplace. This research was triggered by the increasing number of Shopee application users resulting in complaints on the services provided. This research is a type of causal research with a quantitative approach.. The sampling method is purposive sampling counted 113 responder. Data analysis in this study used the path analysis method with the help of PLS. The results of this study indicate that e-service quality and e-recovery service quality have a significant and positive effect on e-customer satisfaction and e-customer loyalty.
\end{abstract}

Keywords: E-Service Quality, E-Recovery Service Quality, E-Customer Satisfaction, E-Customer Loyalty

\begin{abstract}
ABSTRAK
Tujuan dari penelitian ini adalah untuk menemukan dampak e-service quality dan e-recovery service quality terhadap e-customer satisfaction dan e-customer loyalty pada online marketplace Shopee. Penelitian ini dipicu oleh semakin meningkatnya pengguna aplikasi Shopee yang mengakibatkan terjadinya keluhan pada layanan yang diberikan Penelitian ini. merupakan jenis causal research dengan pendekatan kuantitatif. Metode pengambilan sampel adalah purposive sampling sebanyak 113 responden. Analisis data dalam penelitian ini menggunakan metode analisis path dengan bantuan PLS. Hasil penelitian ini menunjukkan bahwa e-service quality dan e-recovery service quality berpengaruh signifikan dan positif terhadap e-customer satisfaction dan e-customer loyalty.
\end{abstract}

Keywords: E-Service Quality, E-Recovery Service Quality, E-Customer Satisfaction, E-Customer Loyalty 


\section{PENDAHULUAN}

Gabungan antara telekomunikasi dan teknologi komputer menghasilkan revolusi di bidang sistem informasi yang membawa dunia memasuki era baru yang semakin cepat. Kemajuan di bidang teknologi, computer dan telekomunikasi mendukung perkembangan internet. Dengan internet pelaku bisnis tidak lagi mengalami kesulitan dalam memperoleh informasi apapun. Rahayu and Day (2015) menyebutkan hubungan antara perdagangan dan teknologi akan terus ada dan berlanjut untuk waktu yang lama. Teknologi informasi dan komunikasi yang berkembang dalam beberapa tahun terakhir menyebabkan perubahan di banyak bidang seperti ekonomi, perdagangan global, perbankan, bea cukai telah berevolusi dan berubah.

Berkembangnya teknologi internet yang membuat pelaku bisnis dengan mudah memperoleh informasi yang dibutuhkan untuk mendukung aktivitas bisnisnya. Dapat dikatakan bahwa seluruh dunia mengakui bahwa internet merupakan peran penting dalam kehidupan masyarakat dan telah menciptakan peluang pekerjaan baru dan evolusi di dalam bisnis dan perdagangan (Apăvăloaiea, 2014). Berkat dampaknya yang luar biasa dan berbuah ekonomi, sains, masyarakat, dan sebagainya, teknologi informasi dianggap sebagai salah satu inovasi terbesar. Penerapan teknologi informasi dalam operasi yang berkaitan dengan proses komersial dan ekonomi telah menyebabkan terciptanya interdisipliner baru yang disebut $e$ commerce, yang memainkan sebuah peran luar biasa dalam urusan ekonomi global (Feizollahi et al., 2014).

Pertumbuhan pangsa pasar e-commerce membuat para pelaku bisnis harus berpikir kreatif untuk menghadapi tantangan persaingan yang semakin tinggi, perusahaan dituntut menentukan terobosan strategi yang berkontribusi secara optimal untuk pencapaian perusahaan.

Terciptanya kepuasan pelanggan dapat dilihat setelah pelanggan melakukan pembelian barang ataupun jasa. Dalam konteks $e$ commerce, e-satisafction dapat dilihat ketika pelanggan menggunakan situs website atau aplikasi tersebut. Jika terjadi kepuasan atau fitur yang disediakan suatu website atau aplikasi e- commerce sesuai dengan harapan dan ekspektasi pelanggan, biasanya pelanggan akan memberikan tanggapan positif dengan mengatakan hal-hal positif dan menjadikan website atau aplikasi e-commerce tersebut tersebut sebagai pilihan utama ketika ingin melakukan pembelian, maka konsumen tersebut disebut konsumen loyal.

Dalam penelitian ini, e-commerce yang diteliti merupakan jenis consumen to consumen (C2C). Dalam C2C, seorang konsumen dapat menjual dan membeli secara langsung pada konsumen lain atau menjual dan membeli produk satu sama lain. Marketplace $\mathrm{C} 2 \mathrm{C}$ yang diteliti merupakan aplikasi marketplace berbasis mobile Shopee yang merupakan anak perusahaan dari Garena yang berbasis di Singapura.

Sebagai marketplace baru, tentu Shopee menghadapi persaingan dengan bisnis $e$ commerce lainnya di Indonesia. Jumlah pengguna yang sangat banyak, tentu tidak menutup kemungkinan untuk terjadinya keluhan mengenai masalah layanan misalnya yang berhubungan dengan kecepatan untuk mengakses aplikasi ataupun masalah transaksi seperti tidak jujurnya pihak penjual dalam mendeskripsikan barang yang akan dijual. Sebagai pihak ketiga, tentu Shopee adalah tempat untuk menerima keluhan jika terjadi kesalahan yang diakibatkan oleh penjual. Sebagai marketplace baru dengan persaingan yang tinggi tentu Shopee harus selalu mempertahankan kualitas layanan,memperbaiki masalah masalah yang terjadi dalam transaksi penjualan dan pembelian pada aplikasi dan mengatasi segala keluhan yang timbul.

\section{KAJIAN PUSTAKA}

Zeithaml, Parasuraman dan Malhotra (2002) dalam Bressolles et al., (2011) mendefinisiakn e-service quality sebagai "sejauh mana situs web memfasilitasi belanja, pembelian dan pengiriman produk dan jasa secara efektif dan efisien". Dalam Tjiptono dan Chandra (2011), Zeithaml et al., mengemukakan empat dimensi utama e-service quality yaitu efficiency, reliability, fulfillment dan privacy.

Istilah recovery service quality mengarah pada tindakan yang dilakukan oleh penyedia 
layanan untuk mengatasi keluhan pelanggan terkait kegagalan layanan yang dirasakan (Gro"nroos, 1988). Tindakan ini dirancang untuk menyelesaikan masalah, mengubah sikap negatif pelanggan yang tidak puas dan akhirnya mempertahankan pelanggan ini (Sousa \& Voss, 2009). Parasuraman et al., (2005) mengemukakan tiga skala e-recovery service quality yang paling banyak digunakan, yaitu : Responsiveness, Fulfillment, dan Contact.

Anderson \& Srinivan (2003) dalam Masomeh (2006:29) mendefinisikan " $E$ satisfaction adalah kepuasan pelanggan yang diberikan terhadap pengalaman pembelian sebelumnya dengan perusahaan perdagangan elektronik". E-customer satisfaction dapat diukur dengan menggunakan dimensi yang dikembangkan oleh Szymansky,Hise (2002) dalam Masomeh (2009:29) yaitu: Convinience, Merchandising, Site Design dan financial security.

Schefter \& Reichheld dalam Suhari (2003:90) menyatakan bahwa e-loyalty berkaitan dengan kualitas dukungan konsumen, pengiriman on-time, presentasi produk, harga pengiriman yang sesuai dan masuk akal, dan privasi yang jelas serta dapat dipercaya. Anderson (2003:13) mengemukakan 5 dimensi e-loyalty, yaitu : Positive word of mouth, Recommend to others, Encourage others to use, First choice for future dan Do more business future.

\section{METODE PENELITIAN}

Desain penelitian ini adalah riset sebab akibat (causal research) untuk memungkinkan dibuatnya kesimpulan sebab-akibat antar variabel. Untuk mengumpulkan data, informasi dan fakta-fakta yang dibutuhkan untuk penelitian ini, maka sumber data dikumpulkan dengan data primer yang didapat dengan teknik pengumpulan data yaitu survei dengan menggunakan angket (kuesioner). Kuesioner tersebut berisi sejumlah pertanyaan filter dan pernyataan yang diambil dari indikator yang dipilih, di mana responden diminta untuk memberikan tanggapan atas pernyataanpernyataan yang sesuai dengan persepsi mereka selama menggunakan aplikasi Shopee untuk melakukan kegiatan jual dan beli yang disebarkan secara online dengan menggunakan bantuan google form kepada pengguna aplikasi Shopee dengan mengirimkan link kuesioner ke beberapa mailing list (kelompok diskusi di Internet). Teknik pengumpulan data secara online dilakukan karena persebaran pengguna Shopee yang menyeluruh di setiap kota di Indonesia, untuk itu pengumpulan data secara offline dirasa kurang efektif. Responden adalah pengguna aplikasi Shopee di seluruh kota di Indonesia dengan sampel sebesar 113.

Tabel 1. Karakteristik Responden

\begin{tabular}{lcc}
\hline $\begin{array}{l}\text { Karakteristik } \\
\text { Demografis }\end{array}$ & $\begin{array}{c}\text { Frekuensi } \\
\text { (f) }\end{array}$ & $\begin{array}{c}\text { Persentasi } \\
(\%)\end{array}$ \\
\hline Jenis Kelamin & & \\
Laki-laki & 40 & 35.40 \\
Perempuan & 73 & 64.60 \\
Umur & & \\
$<21$ Tahun & 10 & 8.85 \\
21-30 Tahun & 90 & 76.65 \\
31-40 Tahun & 11 & 9.73 \\
41-50 Tahun & 2 & 1.77 \\
Pekerjaan & & \\
Belum/tidak bekerja & 9 & 8.0 \\
Ibu Rumah Tangga & 8 & 7.1 \\
Pelajar/Mahasiswa & 45 & 39.8 \\
Pegawai Negri Sipil & 7 & 6.2 \\
Wiraswasta & 13 & 11.5 \\
Karyawan Swasta & 25 & 22.1 \\
Lainnya & 6 & 5.3 \\
\hline
\end{tabular}

Sumber: Data Primer(2018)

Teknik pengolahan data dilakukan dengan menggunakan metode SEM berbasis Partial Least Square (PLS) dengan Software PLS versi $2.0 \mathrm{M} 3$.

Tabel 2. Outer Loadings (Mean, STDEV, TValues)

\begin{tabular}{|c|c|c|c|}
\hline & $\begin{array}{l}\text { Original } \\
\text { Sample } \\
(\mathrm{O})\end{array}$ & $\begin{array}{l}\text { Standard } \\
\text { Deviation } \\
\text { (STDEV) }\end{array}$ & $\begin{array}{l}\text { T Statistics } \\
(|\mathrm{O} / \mathrm{STERR}|)\end{array}$ \\
\hline $\mathrm{X} 1.1<-\mathrm{X} 1$ & 0.945 & 0.013 & 70.544 \\
\hline $\mathrm{X} 1.2<-\mathrm{X} 1$ & 0.927 & 0.018 & 51.811 \\
\hline $\mathrm{X} 1.3<-\mathrm{X} 1$ & 0.888 & 0.036 & 24.764 \\
\hline $\mathrm{X} 1.4<-\mathrm{X} 1$ & 0.872 & 0.032 & 27.146 \\
\hline $\mathrm{X} 2.1<-\mathrm{X} 2$ & 0.925 & 0.017 & 53.501 \\
\hline $\mathrm{X} 2.2<-\mathrm{X} 2$ & 0.893 & 0.019 & 48.217 \\
\hline $\mathrm{X} 2.3<-\mathrm{X} 2$ & 0.881 & 0.028 & 31.339 \\
\hline $\mathrm{Z} .1<-\mathrm{Z}$ & 0.932 & 0.014 & 67.023 \\
\hline $\mathrm{Z} .2<-\mathrm{Z}$ & 0.957 & 0.008 & 122.546 \\
\hline Z. $3<-$ Z & 0.867 & 0.037 & 23.269 \\
\hline Z.4 $<-$ Z & 0.942 & 0.011 & 85.529 \\
\hline$Y .1<-Y$ & 0.945 & 0.012 & 78.941 \\
\hline $\mathrm{Y} .2<-\mathrm{Y}$ & 0.895 & 0.025 & 35.590 \\
\hline$Y .3<-Y$ & 0.908 & 0.031 & 29.546 \\
\hline$Y .4<-Y$ & 0.905 & 0.021 & 42.482 \\
\hline$Y .5<-Y$ & 0.909 & 0.023 & 39.980 \\
\hline
\end{tabular}


Tabel 2. menggambarkan nilai faktor loading (convergent validity) dari setiap indikator. Nilai faktor loading $>0,7$ dapat dikatakan valid, akan tetapi rule of thumbs intrepretasi nilai faktor loading > 0,5 dapat dikatakan valid. Dari tabel ini, diketahui bahwa semua nilai faktor loading dari indikator seluruh variabel lebih besar dari 0,7. Hal ini menunjukan bahwa indikator - indikator tersebut valid.

Tabel 3. Nilai Discriminant Validity (Cross Loading)

\begin{tabular}{|c|c|c|c|c|}
\hline & $\mathrm{X} 1$ & $\mathrm{X} 2$ & $\mathrm{Y} 1$ & $\mathrm{Y} 2$ \\
\hline $\mathrm{X} 1.1$ & $\mathbf{0 . 9 4 5}$ & 0.764 & 0.822 & 0.812 \\
\hline $\mathrm{X} 1.2$ & $\mathbf{0 . 9 2 7}$ & 0.711 & 0.772 & 0.755 \\
\hline $\mathrm{X} 1.3$ & $\mathbf{0 . 8 8 8}$ & 0.772 & 0.780 & 0.760 \\
\hline $\mathrm{X} 1.4$ & $\mathbf{0 . 8 7 2}$ & 0.674 & 0.706 & 0.727 \\
\hline X2.1 & 0.784 & $\mathbf{0 . 9 2 5}$ & 0.793 & 0.764 \\
\hline X2.2 & 0.646 & $\mathbf{0 . 8 9 3}$ & 0.676 & 0.712 \\
\hline X2.3 & 0.738 & $\mathbf{0 . 8 8 1}$ & 0.688 & 0.731 \\
\hline Z.1 & 0.827 & 0.796 & $\mathbf{0 . 9 3 2}$ & 0.858 \\
\hline Z.2 & 0.807 & 0.747 & $\mathbf{0 . 9 5 7}$ & 0.816 \\
\hline Z.3 & 0.727 & 0.651 & $\mathbf{0 . 8 6 7}$ & 0.721 \\
\hline Z.4 & 0.778 & 0.762 & $\mathbf{0 . 9 4 2}$ & 0.811 \\
\hline Y.1 & 0.843 & 0.782 & 0.878 & $\mathbf{0 . 9 4 5}$ \\
\hline Y.2 & 0.736 & 0.742 & 0.754 & $\mathbf{0 . 8 9 5}$ \\
\hline Y.3 & 0.731 & 0.735 & 0.736 & $\mathbf{0 . 9 0 8}$ \\
\hline Y.4 & 0.747 & 0.738 & 0.785 & $\mathbf{0 . 9 0 5}$ \\
\hline Y.5 & 0.774 & 0.735 & 0.799 & $\mathbf{0 . 9 0 9}$ \\
\hline Sumber 1451 & & \\
\hline
\end{tabular}

Sumber: Hasil Analisis PLS, 2019

Tabel 3. menunjukkan semua indikator yang menyusun variabel dalam penelitian ini (nilai yang dicetak tebal) telah memenuhi discriminant validity karena memiliki nilai outer loading terbesar untuk variabel yang dibentuknya dan tidak pada variabel yang lain. Dengan demikian semua indikator di tiap variabel telah memenuhi discriminant validity.

Tabel 4. Nilai R-Square

\begin{tabular}{|l|l|}
\hline Variabel & R Square \\
\hline $\mathbf{Z}$ & 0.7607 \\
\hline $\mathbf{Y}$ & 0.8120 \\
\hline
\end{tabular}

Sumber: Hasil Analisis PLS, 2019

Tabel 4 menunjukan nilai $R$-square untuk variabel $\mathrm{Z}$ diperoleh sebesar 0,7607. Hal ini menunjukkan bahwa $76.07 \%$ variabel $\mathrm{Z}$ dapat dipengaruhi oleh variabel X1 dan X2. Sedangkan sisanya sebesar $23,93 \%$ dipengaruhi oleh variabel lain di luar penelitian. Nilai Rsquare Y sebesar 0,8120 menunjukkan variabel $\mathrm{Y}$ dipengaruhi oleh variabel $\mathrm{X} 1, \mathrm{X} 2$ dan $\mathrm{Z}$ sebesar $81,20 \%$ sedangkan sisanya $18,80 \%$ di pengaruhi oleh variabel lain di luar yang diteliti.

Tabel 5. Path Coefficient (Mean, STDEV, TValues)

\begin{tabular}{|c|c|c|c|}
\hline $\begin{array}{c}\text { Hubungan } \\
\text { Variabel }\end{array}$ & $\begin{array}{c}\text { Original } \\
\text { Sample } \\
(O)\end{array}$ & $\begin{array}{c}\text { Standard } \\
\text { Deviation } \\
(\text { STDEV })\end{array}$ & $\begin{array}{c}T \\
\text { Statistics } \\
(\mid \text { O/STER } \\
R \mid)\end{array}$ \\
\hline $\mathrm{X} 1$-> Y1 & 0.5807 & 0.0846 & 6.8606 \\
\hline $\mathrm{X} 2$-> Y1 & 0.3338 & 0.0875 & 3.8135 \\
\hline $\mathrm{X} 1$-> Y2 & 0.2591 & 0.1206 & 2.1492 \\
\hline $\mathrm{X} 2$-> Y2 & 0.2517 & 0.0952 & 2.6445 \\
\hline $\mathrm{Y} 1$-> Y2 & 0.4467 & 0.117 & 3.8182 \\
\hline
\end{tabular}

Sumber : Hasil Analisis PLS, 2019

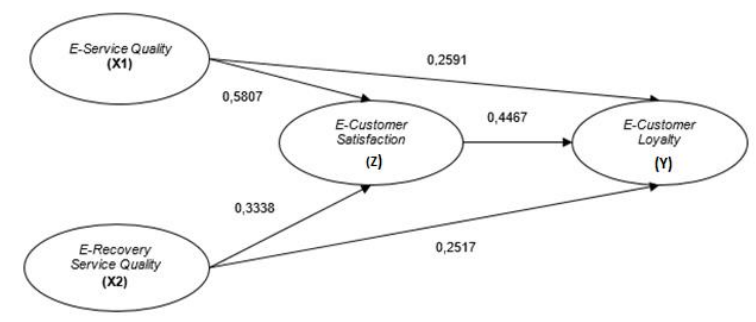

Gambar 1. Model Pengujian Hipotesis

Sumber: Hasil Pengujian Hipotesis

Berdasarkan pada Tabel 5. di dapatkan hasil sebagai berikut :

Persamaam struktural yang didapat adalah :

$Z=0,5807 X_{1}+0.3338 X_{2}$

$Y=0,2591 X_{1}+0.2517 X_{2}+0.4467 Z$

\section{PEMBAHASAN}

Pengaruh E-Service Quality terhadap ECustomer Satisfaction.

Hasil pengujian variabel $\mathrm{X} 1$ terhadap $\mathrm{Z}$ menunjukkan nilai koefisien jalur sebesar 0,5807 dengan nilai t sebesar 6,8606. Artinya, variabel X1 memiliki pengaruh yang signifikan dan positif terhadap $Z$, sehingga Hipotesis 1 diterima.

Hasil penelitian mendukung penelitian Wolfinbarger dan Gilly (2003) didalam Bressolles \& Durrieu (2011) yang mengidentifikasi hubungan positif antara dimensi e-service quality (desain, keandalan, keamanan/privasi, layanan pelanggan) dan 
customer satisfaction, sehingga berkontribusi untuk memuaskan pengguna internet ketika mengunjungi sebuah situs.

Dalam penelitian ini diperoleh bahwa nilai rata-rata dari masing-masing indikator dalam variabel X1 bernilai 3,97. Artinya, responden merasa sangat setuju bahwa e-service quality yang diberikan oleh Shopee Indonesia selama ini adalah baik, ditunjukkan dalam pernyataan responden bahwa Shopee memudahkan untuk mencari apa yang dibutuhkan, Shopee selalu tersedia dan halaman pada aplikasi Shopee tidak bermasalah setelah responden memasukkan informasi pesanan, Shopee membuat janji yang akurat tentang pengiriman produk dan Shopee tidak membagikan informasi pribadi dengan situs lain.

Dari variabel e-customer satisfaction diperoleh bahwa nilai rata-rata sebesar 4,05. Nilai tersebut menunjukkan bahwa dalam penelitian ini responden merasa sangat puas dengan e-service quality yang diciptakan oleh aplikasi Shopee. Rasa puas ini ditunjukkan dengan pernyataan responden bahwa responden menikmati pembelian dengan Shopee, puas melakukan kegiatan pembelian dan penjualan dengan aplikasi Shopee, kinerja dan fitur aplikasi telah memenuhi harapan pelanggan.

\section{Pengaruh E-Service Quality terhadap E- Customer Loyalty.}

Hasil pengujian variabel $\mathrm{X} 1$ terhadap $\mathrm{Y}$ menunjukkan nilai sebesar 0,2591 dengan nilai t sebesar 2,1492. Yang menunjukkan bahwa variabel X1 memiliki pengaruh yang signifikan dan positif secara langsung terhadap Y, sehingga Hipotesis 2 diterima.

Hasil penelitian ini mendukung hasil penelitian Akbar (2016) yang menyatakan bahwa "arah hubungan antara e-service quality terhadap e-customer loyalty adalah positif dan signifikan".

Nilai rata-rata dari indikator dalam variabel e-service quality bernilai 3,97. Artinya, responden setuju dengan pelayanan yang diberikan oleh Shopee Indonesia selama ini adalah baik, ditunjukkan dalam pernyataan responden bahwa Shopee memudahkan untuk mencari apa yang dibutuhkan, Shopee selalu tersedia dan halaman pada aplikasi Shopee tidak bermasalah setelah responden memasukkan informasi pesanan, Shopee membuat janji yang akurat tentang pengiriman produk dan Shopee tidak membagikan informasi pribadi dengan situs lain.

Variabel e-customer loyalty dalam penelitian ini bernilai 4,01 yang menunjukkan bahwa dalam penelitian ini responden merasa sangat setuju bahwa e-customer loyalty pada Shopee adalah baik. Hal ini ditunjukkan dengan pernyataan konsumen yang senang menggunakan aplikasi Shopee, mendorong seseorang untuk berselancar pada aplikasi Shopee, menjadikan Shopee sebagai pilihan pertama dalam melakukan transaksi online dan responden berniat melakukan pembelian ulang dengan aplikasi Shopee.

Pernyataan tersebut sependapat dengan Scheffer \& Reicheld dalam Suhari (2003:90) yang menyatakan bahwa e-loyalty berkaitan dengan kualitas dukungan konsumen, pengiriman on-time, presentasi produk, harga pengiriman yang masuk akal serta privasi yang jelas dan dapat dipercaya.

\section{Pengaruh E-Recovery Service Quality terhadap E-Customer Satisfaction.}

Hasil pengujian X2 terhadap Z menunjukkan nilai koefisien jalur sebesar 0,3338 dengan nilai $\mathrm{t}$ sebesar 3,8135. Hasil ini menunjukkan variabel $\mathrm{X} 2$ berpengaruh signifikan dan positif terhadap $Z$, sehingga Hipotesis 3 diterima.

Dari variabel e-recovery service quality diperoleh bahwa nilai rata-rata sebesar 3,91 yang berarti bahwa responden merasa $e$ recovery service quality yang diciptakan oleh aplikasi Shopee sudah baik, hal ini ditunjukkan dalam pernyataan responden bahwa Shopee memberi tahu apa yang harus dilakukan jika transaksi tidak diproses, Shopee memberikan kompensasi untuk masalah yang diakibatkannya.

E-customer satisfaction dalam penelitian ini memperoleh nilai rata-rata masing-masing indikator sebesar 4,05. Nilai tersebut menunjukkan bahwa dalam penelitian ini responden merasa puas pada e-service quality yang diciptakan oleh aplikasi Shopee. Rasa puas ini ditunjukkan dengan pernyataan responden bahwa responden menikmati pembelian dengan Shopee, puas melakukan kegiatan pembelian dan penjualan dengan aplikasi Shopee, kinerja dan fitur aplikasi telah memenuhi harapan.

Peter \& Olson (2010:387) mengungkapkan "Kepuasan konsumen sebagai sejauh mana 
suatu produk atau jasa memberikan tingkat kesenangan akan konsumsi terkait pemenuhan kebutuhan. Dengan kata lain, sejauh mana kinerja produk melebihi harapan konsumen untuk itu". Hal ini berkaitan dengan instrumen e-recovery service quality yang dikemukakan Parasuraman et al., (2005) yaitu ":responsiveness, compensation dan contact" yang bertujuan untuk memenuhi kebutuhan konsumen dengan cara menanggulangi jika terjadi suatu masalah dalam transaksi penjualan dan pembelian pada Shopee.

\section{Pengaruh E-Recovery Service Quality terhadap E-Customer Loyalty.}

Hasil pengujian menunjukkan nilai koefisien Hasil pengujian hipotesis keempat tentang pengaruh variabel X2 terhadap Y menunjukkan nilai koefisien jalur sebesar 0,2517 dengan nilai $\mathrm{t}$ sebesar 2,6445. Hasil ini berarti bahwa variabel $X 2$ memiliki pengaruh yang positif dan signifikan terhadap $Y$, sehingga Hipotesis 4 diterima.

. Hasil ini mendukung penelitian Zehir dan Narcikara (2016) yang menyatakan "e-recovery service quality berpengaruh signifikan terhadap loyalty". Dimensi yang mempengaruhi loyalty yaitu contact dan responsiveness. Perbaikan dalam infrastruktur situs web dan pengembangan aplikasi untuk dukungan purna jual misalnya aplikasi obrolan online, layanan call center 7-24 dan strategi pemasaran purna jual yang ramah konsumen seperti praktik pengembalian uang dan pengiriman cepat adalah kontributor penting untuk menciptakan loyalitas.

Dari e-recovery service quality diperoleh bahwa nilai rata-rata sebesar 3,91, dimana merasa e-recovery service quality yang diciptakan oleh aplikasi Shopee sudah baik yang ditunjukkan dalam pernyataan responden bahwa Shopee memberi tahu apa yang harus dilakukan jika transaksi tidak diproses, Shopee memberikan kompensasi untuk masalah yang diakibatkannya.

Dalam penelitian ini diperoleh bahwa nilai rata-rata variabel e-customer loyalty bernilai 4,01 yang menunjukkan bahwa responden merasa sangat setuju bahwa e-customer loyalty pada Shopee adalah baik, ditunjukkan dengan pernyataan konsumen yang senang menggunakan aplikasi Shopee, merekomendasikan Shopee kepada orang lain, mendorong seseorang untuk berselancar pada aplikasi Shopee, menjadikan Shopee sebagai pilihan pertama dalam melakukan transaksi online dan responden berniat melakukan pembelian ulang di masa depan dengan aplikasi Shopee.

Dimensi pemulihan yang benar-benar menjelaskan loyalitas adalah responsiveness yang merupakan cara terbaik untuk memulihkan kepercayaan pelanggan setelah mendapatkan pengalaman layanan yang buruk. Sebaliknya, ketersediaan orang sungguhan (contact) tidak signifikan dalam menghasilkan loyalitas.

\section{Pengaruh E-Customer Satisfaction terhadap E-Customer Loyalty.}

Hasil pengujian variabel $\mathrm{Z}$ terhadap $\mathrm{Y}$ menunjukkan nilai koefisien jalur sebesar 0,4467 dengan nilai t sebesar 3,8182 . Hasil ini berarti bahwa variabel $\mathrm{Z}$ berpengaruh positif dan signifikan terhadap variabel $\mathrm{Y}$, sehingga

\section{Hipotesis 5 diterima.}

Hasil penelitian ini mendukung penelitian Tam (2012) yang menyattakan "terdapat hubungan positif antara kepuasan pelanggan dan kesetiaan pelanggan". Fang, Chiu, \& Wang (2011) menyatakan "ketika pelanggan puas dengan sebuah situs, mereka akan bersedia untuk lebih berinteraksi dengan situs tersebut dimasa mendatang dan menjadi pelanggan yang loyal".

Variabel e-customer satisfaction memperoleh nilai rata-rata sebesar 4,05. Nilai tersebut menunjukkan bahwa dalam penelitian ini responden merasa sangat puas dengan pelayanann yang diciptakan oleh aplikasi Shopee. Rasa puas ini ditunjukkan dengan pernyataan responden bahwa responden menikmati pembelian dengan Shopee, puas melakukan kegiatan pembelian dan penjualan dengan aplikasi Shopee, kinerja dan fitur aplikasi telah memenuhi harapan pelanggan.

Dalam penelitian ini juga diperoleh bahwa nilai rata-rata (mean) dari masing-masing indikator dalam variabel e-customer loyalty bernilai 4,01 yang menunjukkan bahwa dalam penelitian ini responden merasa sangat setuju bahwa e-customer satisfaction pada Shopee adalah baik. Hal ini ditunjukkan dengan pernyataan konsumen yang senang menggunakan aplikasi Shopee, mendorong seseorang untuk berselancar pada aplikasi 
Shopee, menjadikan Shopee sebagai pilihan pertama dalam melakukan transaksi online dan responden berniat melakukan pembelian ulang dengan aplikasi Shopee.

Terciptanya kepuasan pelanggan dapat dilihat setelah pelanggan melakukan pembelian barang ataupun jasa. Dalam konteks $e$ commerce, e-satisafaction dapat dilihat ketika pelanggan menggunakan situs website atau aplikasi tersebut. Jika terjadi kepuasan atau fitur yang disediakan suatu website atau aplikasi $e$ commerce sesuai dengan harapan dan ekspektasi pelanggan, biasanya pelanggan akan memberikan tanggapan positif dengan mengatakan hal positif tentang aplikasi dan menjadikannya sebagai pilihan utama ketika ingin melakukan pembelian, dan secara tidak langsung juga, konsumen yang puas akan fitur pada website atau aplikasi e-commerce akan mempengaruhi orang lain untuk menggunakan aplikasi yang sama. Ketika pelanggan berkomitmen untuk menjadikan suatu produk sebagai pilihan utama dalam transaksi bisnis, maka dapat dikategorikan sebagai konsumen loyal. Jadi dapat dikatakan bahwa e-customer loyalty dapat tercipta jika e-customer satisfaction.

\section{KESIMPULAN DAN SARAN \\ Kesimpulan}

Penelitian ini menguji hubungan kausal antara E-Service Quality dan E-Recovery Service Quality terhadap E-Customer Satisfaction dan E-Customer Loyalty pada pelanggan Shopee Indonesia. Hasil penelitian ini menunjukkan bahwa E-Service Quality dan E-Recovery Service Quality berpengaruh positif dan signifikan terhadap E-Customer Satisfaction dan E-Customer Loyalty.

\section{Saran}

Berdasarkan distribusi variabel dapat ditemukan butir dengan penilaian terendah yang dapat mengevaluasi kualitas pelayanan Shopee diantaranya adalah Shopee diharapkan untuk dapat memperbaiki kecepatan loading (memuat) halaman aplikasi. Shopee juga diharapkan untuk memperbaiki layanan untuk menawarkan kemampuan berbicara dengan orang sungguhan jika terjadi masalah, kemudian Shopee diharapkan untuk mempebaiki kinerja dan fitur pada aplikasi agar sepenuhnya memenuhi harapan konsumen dan terakhir Shopee diharapkan untuk terus berinovasi agar unggul dari e-commerce yang lain dan dapat menjadi pilihan pertama konsumen dalam melakukan transaksi online.

\section{DAFTAR PUSTAKA}

Akbar, Djatmiko. 2016. "The Impact of Eservice Quality towards E-Customer Satsifaction and E-Customer Loyalty in Lazada.co.id". Proceeding of Management, vol 3.

Anderson. 2003. "E-Satisfaction and ELoyalty: A Contingency Framework". Psychology \& Marketing, Vol. 20(2): 123138

Apăvăloaiea, Elena-Iulia. 2014. "The impact of the Internet on the business environment". Procedia Economics and Finance 15: 951 - 958.

Buttle, Francis. 2007. "Customer Relationship Management: Concept and Tools", penerbit Bayumedia Publishing, Malang.

Bressolles, Gregory and Durrieu Francois. 2011. Service Quality, Customer Value And Satisfaction Relationship Revisited For Online Wine Websites. AWBR International Conference 9 - 10 June 2011. Bordeaux Management School - BEM France

Fang, Yu-Hui., Chiu, Chao-Min., Wang, Eric T.G. 2011. "Understanding customers' satisfaction and repurchase intentions:An integration of IS succes model, trust, and justice”, Internet Research, Vol. 21 Issue: 4, pp.479-503

Feizollahi, Shirmohammadi, Kahreh, \& Kaherh. 2014. "Investigation the Effect of Internet Technology on Performance of Services Organizations with e-commerce Orientations", social and behavioral sciences 109, 605-609

Irmawati. 2011. "Pemanfaatan E-Commerce dalam Dunia Bisnis". Jurnal Orasi Edisi Ke-VI. 
Komara, Anton Tirta. 2013. "Pengaruh EService Quality dan E-Recovery Service Quality terhadap E-Satisfaction serta Implikasinya pada E-Loyalty Pelanggan Maskapai Penerbangan Air Asia"., Jurnal Ekonomi, Bisnis \& Entrepreneurship Vol. 7, No. 2, 105-115.

Marimon Frederic, Luc Honore Petnji Yaya \& Marti Casadesus Fa. 2012. "Impact of eQuality and service recovery on loyalty: A study of e-banking in Spain, Total Quality". Management \& Business Excellence, 23:78, 769-787

Matos, de, Celso Augusto., Ituassu, Cristiana Trindade \& Rossi, Carlos Alberto Vargas. 2007, "Consumer attitudes toward counterfeits: a review and extension", Journal of Consumer Marketing, Vol. 24 Iss 1 pp. $36-47$

Parasuraman, A. Zeithaml, V.A., Malhorta, A. (2005). E-S-QUAL, a Multiple-Item Scale for Assessing Electronic and Revolution in Web Site Functionalities. Decision Sciences, 35(3), 423-455.

Kang, Byung-Suh., Cho, Chul-Ho., Baek, JongDeuk. 2007. "The Effects of Service Quality on Customer Satisfaction in Case of Dissatisfied Customers", Asian Journal on Quality, Vol. 8 Iss 1 pp. 27 - 39

Pina, Vicente., Torres, Lourdes., Bachiller, Patricia. 2014. "Service quality in utility industries: The European telecommunications sector", Managing Service Quality: An International Journal, Vol. 24 Issue: 1, pp.2-22

Peter, Paul J., Jerry C. Olson. 2010. Consumer Behavior and Marketing Strategy, Ninth Edition (New York: McGraw-Hill Companies. 2010), p.387

Rahayu, Rita, John Day. 2015. "Determinant Factors of E-commerce Adoption by SMEs in Developing Country: Evidence from Indonesia". Social and Behavioral Sciences 195,142 - 150 .

Sousa, Rui, Voss,Christopher. 2002. "Quality Management re-visited: a reflective review and agenda for future research". Journal of operations Management. 91-109

Suhari, Y. 2003. Meningkatkan E-Loyalitas (Model dan Kerangka Kerja Konseptual). Dinamik, 8(1). 90

Tjiptono dan Chandra. 2011. Service Quality \& Satisfaction, Edisi 3. Penerbit Andi. Yogyakarta.

Wolfinbarger, M., \& Gilly, M. (2003). E-TailQ: dimensionalizing, measuring, and predicting retail quality. Journal of Retailing, 79, 183-193.

Zehir, Narcikara. 2016. "E-Service Quality and E-Recovery Service Quality: Effects on Value Perceptions and Loyalty Intentions". Social and Behavioral Sciences 229, 427 443

Zeithaml, Valarie A., Parasuraman, A., \& Malhotra, Arvind. (2002). Service quality delivery through web sites: A critical review of extant knowledge. Journal of the Academy of Marketing Science, 30(Fall), 362-410. 